\title{
Coexistence of gastrointestinal stromal tumor of the stomach and small bowel adenocarcinoma: A case report
}

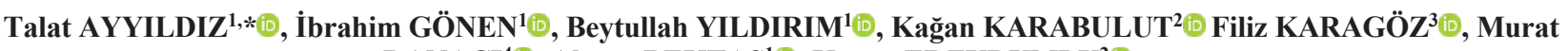 \\ DANACI ${ }^{4}{ }^{\circ}$, Ahmet BEKTAŞ ${ }^{1}$, Kenan ERZURUMLU2 ${ }^{2}$
}

\begin{abstract}
${ }^{1}$ Department of Gastroenterology, Medical Faculty, Ondokuz Mayıs University, Samsun, Turkey
${ }^{2}$ Department of General Surgery, Medical Faculty Ondokuz Mayıs University, Samsun, Turkey

${ }^{3}$ Department of Pathology, Medical Faculty, Ondokuz Mayıs University, Samsun, Turkey

${ }^{4}$ Department of Radiology, Medical Faculty, Ondokuz Mayıs University, Samsun, Turkey
\end{abstract}

\begin{abstract}
\begin{tabular}{ccccc}
\hline Received: 24.11 .2020 & $\bullet$ & Accepted/Published Online: 28.03 .2021 & Final Version: 23.04 .2021 \\
\hline
\end{tabular}
\section{Abstract}

The coexistence of gastrointestinal tumors (GIST's) with other several primary malignant neoplasms has been demonstrated. However, there is no study that reported simultaneous occurrence of primary small bowel adenocarcinoma (SBA) and a GIST located in the stomach. Here, we report the first case of SBA and a synchronous gastric GIST. Surgical resection and clinicopathological characterization were performed for the masses identified through endoscopic and radiologic studies. Computed tomography scan showed a $13 \mathrm{~mm}$ mass located at the gastric antrum and another mass lesion partially occluding the jejunum. A biopsy specimen was obtained from the mass at the proximal jejunum by enteroscopy. The tumor was reported as adenocarcinoma. The patient was operated by the general surgery team. The features of the submucosal lesion resected from the antrum were consistent with a diagnosis of a GIST which contained spindle cells and showed positive staining with CD-117 and CD34. Mitosis was not observed, and $\mathrm{Ki} 67$ index was below $10 \%$. This is the first case of coexistence of GIST of the stomach and SBA to be reported in English-language literature. The prominent characteristics of our case include its antral localization, male sex, absence of mitosis and incidental diagnosis.
\end{abstract}

Keywords: GIST, small bowel adenocarcinoma, gastric tumor, submucosal lesion

\section{Introduction}

Gastrointestinal stromal tumors are the most prevalent mesenchymal tumors of the gastrointestinal tract (Corless et al., 2011). Approximately one-third of GIST's are discovered during investigations and treatment procedures undertaken for other disorders (Agaimy et al., 2006). GIST's have been shown to coexist with other type of cancers either synchronously or metachronously (Gonçalves et al., 2010). There are studies which reported the concurrent occurrence of a GIST originating from the small intestine and gastric carcinoma (Karahan et al., 2013).

However, the coexistence of a primary SBA with a GIST located in the stomach has not been reported previously. Here, we report the first case of coexistence of a surgically resected SBA with a gastric GIST incidentally detected in a patient with nausea and vomiting and discuss it in light of clinical, radiological, endoscopic and histopathological findings.

\section{Case report}

A 79-year-old patient presented with a history of aggravating nausea, vomiting and abdominal bloating in the last 3-4 months. His personal history included essential hypertension. During physical examination, abdominal guarding was not observed, and bowel sounds were normoactive.

Laboratory investigations showed the following results: Haemoglobin $13.40 \mathrm{~g} / \mathrm{dL}$, White Blood Cell count 7080/ $\mu \mathrm{L}$ and CRP $<3.36 \mathrm{mg} / \mathrm{L}$. Computed tomography (CT) scan revealed a round shaped, heterogeneous mass lesion with a diameter of $13 \mathrm{~mm}$ in the posterior wall of gastric antrum which showed a marked contrast uptake and slight protrusion out of the wall and into the lumen (Fig. 1). During upper gastrointestinal endoscopy, a submucosal lesion was detected at the prepyloric antrum. Double balloon enteroscopy showed a mass lesion obstructing the lumen at the proximal jejunum and biopsy specimens were obtained (Fig. 2). Adenocarcinoma was diagnosed by pathological examination (Fig. 3).

The patient was operated by the general surgery team. Histopathological examination showed that the submucosal lesion resected from the antrum was consistent with a gastrointestinal stromal tumor composed of spindle cells. The tumor showed diffuse and strong positive staining with CD117 and CD-34 and no staining with SMA, Desmin and S100 (Fig. 4). Mitosis was absent and Ki67 index was below 10 percent. The mass obtained from the proximal of jejunum was 
Ayyıldız et al. / J Exp Clin Med

$2.3 \times 2 \times 1.7 \mathrm{~cm}$ in size. As a result, the tumor was reported as pT3N1Mx, well-differentiated small bowel adenocarcinoma.

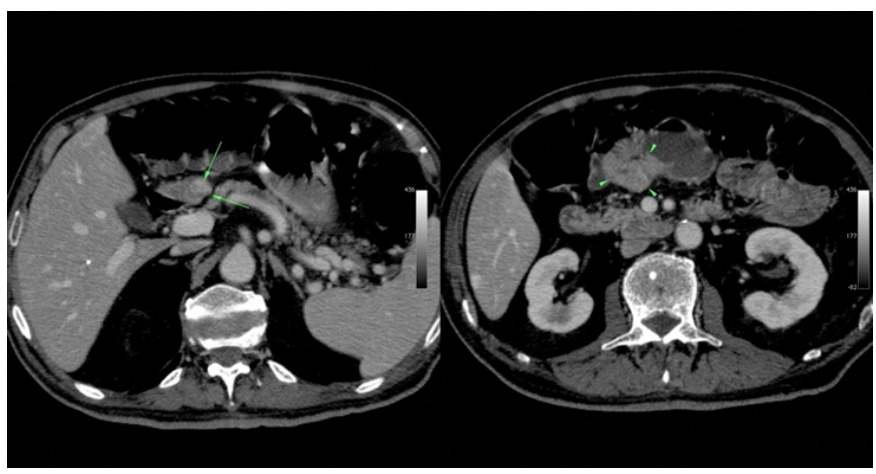

Fig. 1. A solid, round shaped, well-defined mass (arrows) located in the gastric wall and another mass (arrow heads) that resulted in symmetrical thickening of the wall at the level of small bowel in contrast-enhanced sections as shown by abdominal computed tomography

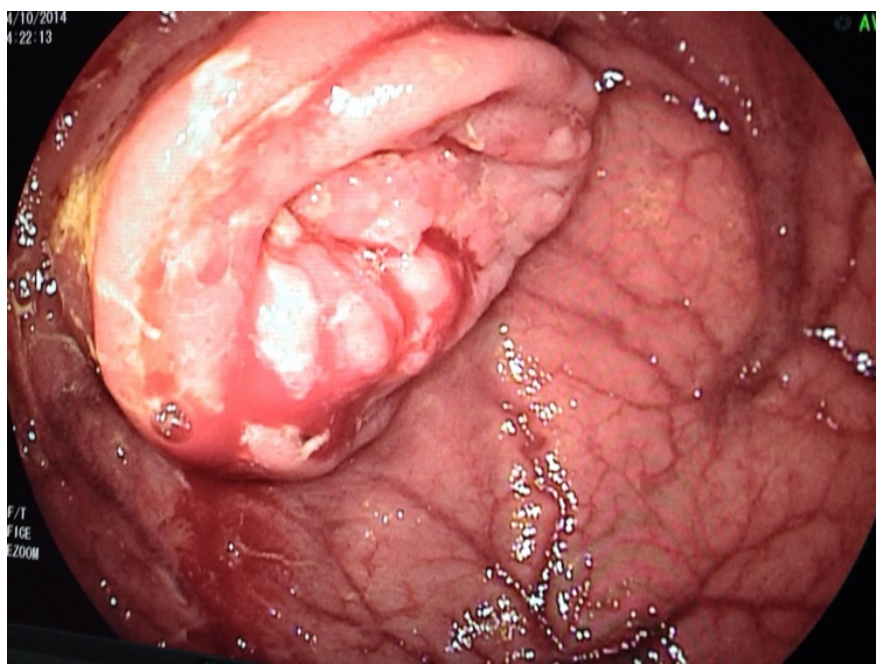

Fig. 2. Double balloon enteroscopy showed a mass lesion obstructing the lumen at the proximal jejunum

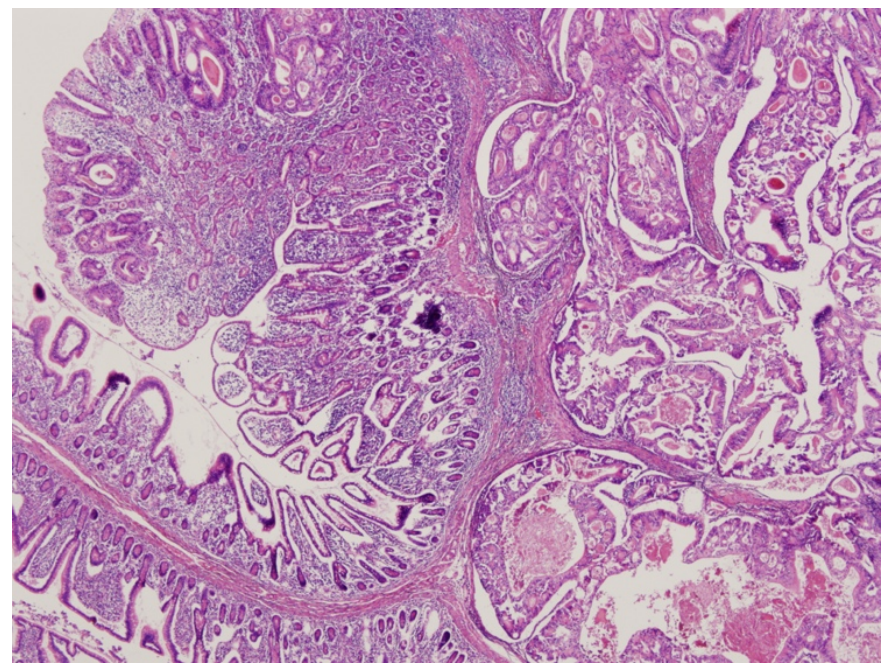

Fig. 3. A well differentiated adenocarcinoma resected from the small bowel (H-Ex40)

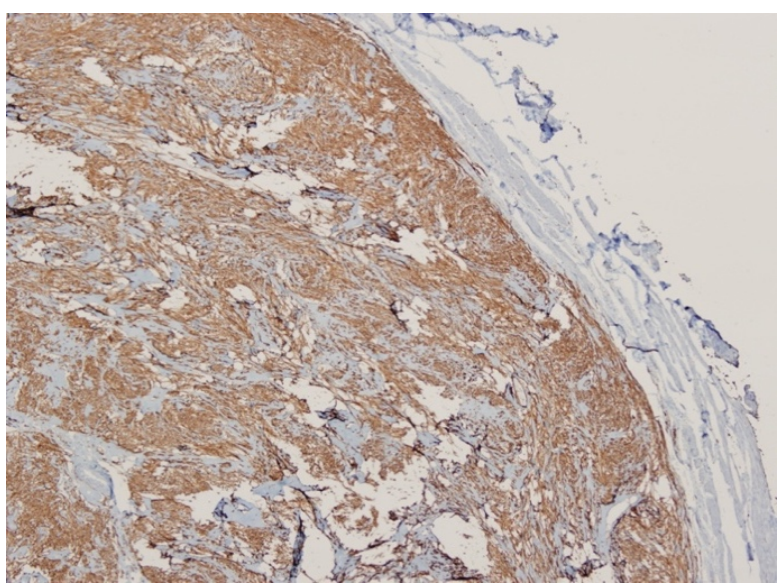

Fig. 4. Immunohistochemical $\mathrm{CD}-117$ positivity shown in a gastrointestinal stromal tumor located in the stomach

\section{Discussion}

Stromal and mesenchymal tumors typically affect gastrointestinal tract and are commonly located in the stomach (50-60\%) and small bowel (30-35\%). However, they may occur anywhere along the digestive tract including mesentery, omentum and peritoneum (Corless et al., 2011; Joensuu et al., 2013).

The most common symptoms include bleeding into the intestine or abdominal cavity, anemia and abdominal pain as well as dyspepsia, nausea, vomiting, constipation or diarrhea, frequent urination and fatigue (Mucciarini et al., 2007; Caterino et al., 2011; Bümming et al., 2006).

Morphologically, GIST's are categorized into three groups as spindle cell, epitheloid and mixed by pathological examination (Kindblom et al., 1998; Fletcher et al., 2002). KIT (CD-117) and anoctamin (ANO1) are the two markers with greatest sensitivity and specificity for GIST's (Sarlomo-Rikala et al., 1998; West et al., 2004). Five percent of GIST's are negative for KIT expression but most of these express ANO1 (Medeiros et al., 2004). Masses suspected or diagnosed to be GIST should be removed if they are $2 \mathrm{~cm}$ or greater in size. However, smaller tumors may be excised or followed endoscopically at intervals of 6 to 12 months. Complete (R0) resection of GIST's is the primary goal of surgical treatment (Hohenberger et al., 2010).

Primary small bowel malignancies are rare tumors and account for $1-3 \%$ of gastrointestinal tumors (Gill et al., 2001). Malignancies that occur in the small bowel include carcinoid tumors, adenocarcinoma, lymphoma and sarcoma (Bilimoria et al., 2009).

Symptomatic tumors usually present at an advanced stage and $50 \%$ of cases show metastasis (Talamonti et al., 2002). SBA represents $33 \%$ of primary small bowel cancers, most commonly affecting duodenum followed by jejunum and ileum (Bilimoria et al., 2009).

In recent years, an increase has been seen in the diagnosis of GIST with synchronous malignancies mainly as a result of 
advances in imaging techniques. Congenital genetic defects, exogenous factors, common pathophysiology and underlying immune suppression have all been implicated to contribute to the development of double primary neoplasms (Dasanu et al., 2011).

We did not identify any articles published in Englishlanguage literature that reported on the coexistence of gastric GIST and small bowel adenocarcinoma through PubMed search. In this regard, our case is the first such case to be reported. The lesions were visualized radiologically and endoscopically and characterized by histopathological examination of surgically resected materials. There are several case reports published in literature describing coexistence of GIST with malignancies including gastric carcinoma, gastric lymphoma, colon carcinoma, pancreatic carcinoid tumor and pancreatic adenocarcinoma (Agaimy et al., 2006). These publications reported low mitotic activity in GIST's coexisting with synchronous and other malignancies (Maiorana et al., 2000).

Contrastingly, GIST located in the stomach did not show mitotic activity in our case. The prominent characteristics of our case include its antral localization, male sex, absence of mitosis and incidental diagnosis. As known, gastric localization is frequent among GIST's. However, it should be borne in mind that, although rarely, other primary malignancies located in the gastrointestinal tract may occur concomitantly with GIST.

\section{Conflict of interest}

None to declare.

\section{Acknowledgments}

None to declare.

\section{References}

1. Agaimy, A., Wünsch, P. H., Sobin, L. H., Lasota, J., Miettinen, M., 2006. Occurrence of other malignancies in patients with gastrointestinal stromal tumors. Semin. Diagn. Pathol. 23, 120129.

2. Bilimoria, K. Y., Bentrem, D. J., Wayne, J. D., Ko, C. Y., Bennett, C. L., Talamonti, M. S., 2009. Small bowel cancer in the United States: changes in epidemiology, treatment, and survival over the last 20 years. Ann. Surg. 249, 63-71.

3. Bümming, P., Ahlman, H., Andersson, J., Meis-Kindblom, J. M., Kindblom, L. G., Nilsson, B., 2006. Population-based study of the diagnosis and treatment of gastrointestinal stromal tumours. Br. J. Sur. 93, 836-843.

4. Caterino, S., Lorenzon, L., Petrucciani, N., Iannicelli, E., Pilozzi, E., Romiti, A., Cavallini, M., \& Ziparo, V., 2011. Gastrointestinal stromal tumors: correlation between symptoms at presentation, tumor location and prognostic factors in 47 consecutive patients. World. J. Surg. Oncol. 9, 13

5. Corless, C. L., Barnett, C. M., Heinrich, M. C., 2011. Gastrointestinal stromal tumours: origin and molecular oncology. Nat. Rev. Cancer. 11, 865-878.

6. Dasanu, C. A., Mesologites, T., Trikudanathan, G., 2011.
Synchronous tumors: adenosquamous carcinoma of pancreas and GIST of stomach. J. Gastrointest. Cancer. 42, 186-189.

7. Fletcher, C. D., Berman, J. J., Corless, C., Gorstein, F., Lasota, J., Longley, B. J., Miettinen, M., O'Leary, T. J., Remotti, H., Rubin, B. P., Shmookler, B., Sobin, L. H., Weiss, S. W., 2002. Diagnosis of gastrointestinal stromal tumors: A consensus approach. Hum. Pathol. 33, 459-465.

8. Gill, S. S., Heuman, D. M., Mihas, A. A., 2001. Small intestinal neoplasms. J. Clin. Gastroenterol. 33, 267-282.

9. Gonçalves, R., Linhares, E., Albagli, R., Valadão, M., Vilhena, B., Romano, S., Ferreira, C. G., 2010. Occurrence of other tumors in patients with GIST. Surg. Oncol. 19, e140-e143.

10. Hohenberger, P., Ronellenfitsch, U., Oladeji, O., Pink, D., Ströbel, P., Wardelmann, E., Richard, P., 2010. Pattern of recurrence in patients with ruptured primary gastrointestinal stromal tumour. Br. J.Surg. 97, 1854-1859.

11. Joensuu, H., Vehtari, A., Riihimäki, J., Nishida, T., Steigen, S. E., Brabec, P., Plank, L., Nilsson, B., Cirilli, C., Braconi, C., Bordoni, A., Magnusson, M. K., Linke, Z., Sufliarsky, J., Federico, M., Jonasson, J. G., Dei Tos, A. P., Rutkowski, P., 2012. Risk of recurrence of gastrointestinal stromal tumour after surgery: an analysis of pooled population-based cohorts. Lancet Oncol. 13, 265-274.

12. Karahan, N., Başpinar, Ş., Bozkurt, K. K., Devrım, T., Kapucuoğlu, F. N., 2013. Nörofibromatozis Tip-1'li Hastada Multipl Gastrointestinal Stromal Tümör ve Midede Taşlı Yüzük Hücreli Karsinom Birlikteliği: Olgu Sunumu [Coexistence of multiple gastrointestinal stromal tumors and signet ring cell carcinoma of stomach in a patient with neurofibromatosis type-1: case report]. Turk. Patoloji. Derg. 29, 64-68.

13. Kindblom, L. G., Remotti, H. E., Aldenborg, F., Meis-Kindblom, J. M., 1998. Gastrointestinal pacemaker cell tumor (GIPACT): gastrointestinal stromal tumors show phenotypic characteristics of the interstitial cells of Cajal. Am. J. Pathol.152, 1259-1269.

14. Maiorana, A., Fante, R., Maria Cesinaro, A., Adriana Fano, R., 2000. Synchronous occurrence of epithelial and stromal tumors in the stomach: a report of 6 cases. Pathol. Lab. Med. 124, 682-686.

15. Medeiros, F., Corless, C. L., Duensing, A., Hornick, J. L., Oliveira, A. M., Heinrich, M. C., Fletcher, J. A., Fletcher, C. D., 2004. KIT-negative gastrointestinal stromal tumors: proof of concept and therapeutic implications. Am. J. Surg. Pathol. 28, 889-894.

16. Mucciarini, C., Rossi, G., Bertolini, F., Valli, R., Cirilli, C., Rashid, I., Marcheselli, L., Luppi, G., Federico, M., 2007. Incidence and clinicopathologic features of gastrointestinal stromal tumors. A population-based study. BMC. Cancer. 7, 230.

17. Sarlomo-Rikala, M., Kovatich, A. J., Barusevicius, A., Miettinen, M., 1998. CD117: a sensitive marker for gastrointestinal stromal tumors that is more specific than CD34. Mod. Pathol. 11, 728734.

18. Talamonti, M. S., Goetz, L. H., Rao, S., Joehl, R. J., 2002. Primary cancers of the small bowel: analysis of prognostic factors and results of surgical management. Arch. Surg. 137, 564-571.

19. West, R. B., Corless, C. L., Chen, X., Rubin, B. P., Subramanian, S., Montgomery, K., Zhu, S., Ball, C. A., Nielsen, T. O., Patel, R., Goldblum, J. R., Brown, P. O., Heinrich, M. C., van de Rijn, M., 2004. The novel marker, DOG1, is expressed ubiquitously in gastrointestinal stromal tumors irrespective of KIT or PDGFRA mutation status. Am. J. Pathol. 165, 107-113. 